\title{
Lo maravilloso y mágico del neurodesarrollo humano
}

\author{
FERNANDO PINTO L. ${ }^{1}$ \\ 1. Pediatra, Neurólogo Infantil, Profesor Titular, Facultad Medicina Universidad de Chile, Past-Presidente SOCHIPE, \\ Jefe Servicio Pediatría Hospital Regional Coyhaique.
}

Palabras clave: Neurodesarrollo, programación, encéfalo, neuroplasticidad, apego.

La secuencia del Neurodesarrollo en el hombre, desde que el óvulo es penetrado por el espermio hasta que el individuo llega al estado adulto, adquiriendo y desechando un sinnúmero de capacidades y funciones, corresponde al proceso más complejo y, a la vez, perfecto de la naturaleza toda. Tan perfecto, que algunos científicos aseguran que es el resultado de una programación divina y ello confirmaría la existencia de Dios.

Para los científicos agnósticos y algunos ateos, gran parte de la explicación provenía de la teoría de Darwin, de la "evolución de las especies", en el siglo XIX, quien falleció sin haber encontrado el "eslabón perdido", que otorgara solidez definitiva e irrebatible a su teoría, sin embargo, nos permitió comprender que la Ontogenia es una recapitulación de la Filogenia.

Hoy, en el siglo XXI, con los notables avances tecnológicos y científicos en diversas áreas, especialmente en embriología, genética, neurofisiología y otras, como el enorme aporte de la computación, que nos ha permitido comprender un poco más esta maravilla evolutiva, podemos afirmar que el neurodesarrollo es más aún que una recapitulación de la Filogenia: es una recapitulación del Cosmos, desde el "Bing-Bang" hasta nuestros días, desde los primeros átomos, moléculas y ADN, hasta el complejo ser huma- no, su inteligencia y sus infinitas potencialidades.

La temática del neurodesarrollo, que se expresa en lo que conocemos como "Desarrollo Psicomotor", no preocupó a los médicos antes del siglo XVI, cuando recién se comienza a acuñar el concepto de "Infancia" y sólo en el siglo XVIII se comprende al niño como un ente diferente al adulto. En el año 1774, Johann Heinrich Pestalozzi comienza las primeras descripciones del desarrollo del niño y su secuencia. En el siglo XX se desarrolla la Pediatría, en todas sus áreas y sólo, a partir del año 1990 comienza a estudiarse el desarrollo infantil, desde la perspectiva de la neurociencia y se comprende que el desarrollo psicomotor es una consecuencia de la interacción entre la genética y el medio ambiente, expresados en el desarrollo cerebral, con la participación de más de 30.000 genes para construir esta obra.

Tras las primeras secuencias embriológicas que llevan a la "Gastrulación", cuando nace el Sistema Nervioso Central, pasando por el proceso Notocordial y luego la Inducción Dorsal y Ventral, en las primeras semanas tras la fecundación, se avanza hacia la etapa de "Proliferación", entre el $2^{\circ}$ y $4^{\circ}$ mes de gestación, cuando aumenta el número de neuronas y células de la glía, para continuar con el proceso de "Migración", cuando las neuronas viajan desde las zonas centrales hasta la periferia, para formar la corteza cerebral, entre el $3^{\circ}$ y $5^{\circ}$ mes, para luego comenzar el complejo proceso de "Orga-

Correspondencia a:

Fernando Pinto Laso

E-mail:fp@entelchile.net 
nización", que comienza en el $6^{\circ}$ mes, pero continúa varios meses después del nacimiento, con la arborización de las dendritas, que establecen cada día millones de circuitos, algunos que persisten y otros que desaparecen, para dar paso a otros más complejos (apoptosis: muerte celular programada). Finalmente el último y más prolongado proceso: la "Mielinización", que comienza alrededor del nacimiento y se extiende por varios años, permitiendo el aislamiento de circuitos y mejorando la velocidad de conducción nerviosa.

Este conocimiento, netamente descriptivo, se enfrenta hoy a la programación genética molecular, que corresponde a la embrio-genética moderna, donde se describen programas genéticos predefinidos que dirigen y coordinan la diferenciación celular y tisular y permite entender, con mayor precisión, las secuencias temporales y espaciales de los cambios estructurales y funcionales que va experimentando el cerebro. Este es el "eslabón perdido" de Darwin, que la ciencia, hoy está próxima a dirimir.

La interacción de múltiples y variados genes, algunos organizadores, otros reguladores o inhibidores, programan sincrónicamente el neurodesarrollo y cualquier alteración o problema de alguno de ellos, ya sea de manera directa o indirecta, se traduce en una patología del Sistema Nervioso Central, con severas repercusiones en el desarrollo psicomotor. Todas las características definidas a nivel de nuestro genoma, son sometidas a interacción con el medio ambiente, el cual puede introducir modificaciones positivas o negativas para el neurodesarrollo).

Esta programación, pulida y perfeccionada, tras millones de años de evolución, que comenzamos a comprender, nos abre las puertas a la "Neuroprevención", "Neuroprotección" y "Neurotratamiento".

Ahora comprendemos cómo el ácido fólico, el ácido retinoico, el alcohol, la cocaína, los pesticidas, algunos fármacos, las radiaciones, etc., pueden interferir con el normal desarrollo de nuestro cerebro y ello nos permite dar los primeros pasos en lo que es la "Neuroprevención". La adición de Ac. Fólico en la harina de trigo, es un hito mundial de neuroprevención en nuestro país y de ello se ha desprendido la evidencia de una importante disminución de los defectos del tubo neural en los recién nacidos chilenos.

El cerebro de un recién nacido pesa alrededor de 350 gramos, a los 2 años 1050 y en el adulto 1400 gramos. El encéfalo sobreproduce sinapsis los primeros tres años, aquellas que mantienen estímulos prevalecen y las subestimuladas desaparecen. Aquí está la clave del rol que ejerce el medio ambiente, que ejerce influencias en la arquitectura cerebral y sus funciones.

Como el cerebro humano es el único cerebro de mamíferos que no ha completado su desarrollo al nacer es obvio que la continuación de su proceso depende de dos grandes factores: $1^{\circ}$ la leche materna, específica para la especie humana, que aporta valiosos nutrientes, que ninguna otra leche mamífera puede brindar, para concluir el neurodesarrollo y en $2^{\circ}$ lugar el apego, que es la mayor influencia del medio ambiente en el adecuado desarrollo psicomotor. Abundan las investigaciones, filtradas por la medicina de las evidencias, que demuestran que los niños alimentados al menos los primeros 6 meses de vida con leche materna, enferman menos y son más inteligentes y al tener mejor Apego, son más seguros, estables, con menos maltrato, con familia más funcional y con un sistema inmunológico más potente. Se ha descrito, por ejemplo, que el maltrato infantil es capaz de disminuir el volumen cerebral y el número de sinapsis, como una influencia negativa del medio ambiente, al igual que el alcohol y muchas drogas.

El desarrollo psicomotor es individual y con transiciones. Es un proceso de cambio sistemático, gradual, adaptativo, donde es necesario perder algunas funciones para poder adquirir otras. (por ej. no es posible lograr la aprehensión voluntaria a los 3 meses, si no ha desaparecido el reflejo de aprehensión involuntario. Tampoco es posible saltar etapas, según la comprobada teoría de J. Piaget "es imposible caminar si no se aprendió a pararse, y menos correr, si no se sabe caminar", lo que es aplicable a la mayoría de las áreas del neurodesarrollo.

Otra gran verdad: "Las experiencias tempranas marcan las conecciones cerebrales y, por ende, el futuro del ser humano". El Dr. K. 
Swaiman, brillante neurólogo infantil norteamericano y autor de varios textos, señalaba, al respecto, hace más de una década, "El futuro del hombre está en el cerebro de los niños. Si cuidamos el cerebro de los recién nacidos y niños, estaremos cuidando a la humanidad".

En el neurodesarrollo existen elementos de extrema importancia, que se dividen en:

- "Período Crítico", que es una ventana en el tiempo que permite el desarrollo de una determinada habilidad. Por ejemplo: La visión y audición se desarrollan primordialmente desde el nacimiento hasta los 5 meses de edad. Posteriormente, una catarata congénita o una sordera anatómica no operadas, dejan secuelas irrecuperables. El lenguaje, entre el $1^{\circ}$ y $8^{\circ}$ año de vida. Luego no es rehabilitable de manera efectiva. Así sucede con otras habilidades.

- "Período Sensible", otra ventana más amplia, que permite cierto aprendizaje y que corresponde a los períodos en que es posible incorporar nuevas habilidades. Depende, en parte, de la capacidad de crear nuevas sinapsis y en cerebros exigidos, puede extenderse por mucho tiempo.

Pero, indudablemente el elemento más apasionante es el de la "Neuroplasticidad", que corresponde a la capacidad del cerebro de responder y reorganizarse frente a noxas que lo afecten seriamente y esta condición es propia de la primera década de vida. Por ejemplo: Cuando un adulto padece de un accidente vascular en su arteria cerebral media izquierda, esto determina, necesariamente una afasia y una hemiparesia o hemiplejia derecha, con un pobre porcentaje de recuperación. Si lo mismo ocurre en un niño de tres años, sucede lo mismo, pero al cabo de tres meses el niño recupera completamente el lenguaje y a la vez, su hemiplejia se atenúa o desaparece. Esto se explica, porque en el cerebro joven existe plasticidad, es decir, la capacidad de reasumir las mismas funciones con otras áreas cerebrales, a través de nuevas interconexiones. Esta Neuroplasticidad puede ser Reactiva, como manera de ajustarse frente a agresiones, Adaptativa, como una capacidad de readaptar los circuitos neuronales, Reestructuradora, recuperando funciones perdidas o Evolutiva, interactuando plásti- camente con el medio ambiente.

Resulta claro, que muchos factores pueden interferir el neurodesarrollo, tanto desde el punto de vista intrínseco, como genéticos, estructurales y metabólicos, como extrínseco, agregando en esta lista el stress, los traumas, toxinas, accidentes vasculares, tumores, etc.

Si sólo analizamos el stress, en los tres primeros años de vida, podemos observar que éste es capaz de aumentar la producción de glucocorticoides, a través del eje hipotálamohipofisario, lo que, se ha demostrado, es capaz de generar cambios permanentes en el cerebro en desarrollo.

Pero finalmente y quizás lo más importante es que cualquier tipo de stress, en los primeros meses de vida, interfiere al Apego y la Lactancia Materna, lo que demostradamente se traduce en disminución de las conexiones neuronianas, con aumento de la apoptosis (autodestrucción de neuronas, antes del tiempo ideal) y que en la práctica significa menos inteligencia global y emocional, mayor riesgo de maltrato infantil, mayor vulnerabilidad frente a infecciones y menores índices de salud en general.

Lo que permitió que los mamíferos sobrevivieran a los dinosaurios y otras especies y que, posteriormente el hombre, pese a los períodos glaciales y otros desastres de la naturaleza, también sobreviviera y continuara evolucionando en su genoma e inteligencia, no es sino merced a la lactancia natural y el apego, que brindaron los nutrientes específicos y los estímulos ambientales necesarios para un adecuado y progresivo neurodesarrollo.

Triste es, en el siglo XXI, constatar que pese a nuestra civilización y desarrollo científico logrado, el ser humano sea el único mamífero del planeta, que por razones sociológicas y políticas inadecuadas, no puede completar su neurodesarrollo como es debido, por no estar protegida con una adecuada lactancia materna y apego. En nuestra legalidad está penalizado el aborto, pero curiosamente está permitido y legalizado el abortar la lactancia natural y el apego, interrumpiendo el normal desarrollo psicomotor, a través de una licencia postnatal insuficiente para los requerimientos biológicos del ser humano, en desacuerdo con las evidencias científicas claramente conocidas. 